\title{
Quality of terrestrial data derived from UAV photogrammetry: A case study of Hetao irrigation district in northern China
}

\author{
Hongming Zhang ${ }^{1 \mathrm{a}}$, Jiangtao Yang ${ }^{1 \mathrm{~b}}$, Jantiene E.M. Baartman ${ }^{2}$, Shuqin $\mathrm{Li}^{1 \mathrm{ia}}$, Bei Jin ${ }^{1 \mathrm{c}}$, \\ Wenting $\operatorname{Han}^{1 \mathrm{~d}^{*}}$, Xiaomei Yang ${ }^{1 \mathrm{e}, 2}$, Lingtong Gai ${ }^{2}$, Coen J. Ritsema ${ }^{2}$, Violette Geissen ${ }^{2}$ \\ (1a. College of Information Engineering; 1b. College of Water Resources and Architectural Engineering; \\ 1c. College of Economics and Management; 1d. Institute of Soil and Water Conservation; \\ 1e. College of Natural Resources and Environment, Northwest A\&F University, Yangling 712100, Shaanxi, China; \\ 2. Soil Physics and Land Management Group, Wageningen University, PO Box 47 6700AA Wageningen, the Netherlands)
}

\begin{abstract}
Most crops in northern China are irrigated, but the topography affects the water use, soil erosion, runoff and yields. Technologies for collecting high-resolution topographic data are essential for adequately assessing these effects. Ground surveys and techniques of light detection and ranging have good accuracy, but data acquisition can be time-consuming and expensive for large catchments. Recent rapid technological development has provided new, flexible, high-resolution methods for collecting topographic data, such as photogrammetry using unmanned aerial vehicles (UAVs). The accuracy of UAV photogrammetry for generating high-resolution Digital Elevation Model (DEM) and for determining the width of irrigation channels, however, has not been assessed. A fixed-wing UAV was used for collecting high-resolution $(0.15 \mathrm{~m})$ topographic data for the Hetao irrigation district, the third largest irrigation district in China. 112 ground checkpoints (GCPs) were surveyed by using a real-time kinematic global positioning system to evaluate the accuracy of the DEMs and channel widths. A comparison of manually measured channel widths with the widths derived from the DEMs indicated that the DEM-derived widths had vertical and horizontal root mean square errors of 13.0 and $7.9 \mathrm{~cm}$, respectively. UAV photogrammetric data can thus be used for land surveying, digital mapping, calculating channel capacity, monitoring crops, and predicting yields, with the advantages of economy, speed and ease.
\end{abstract}

Keywords: UAVs, GIS, DEM, irrigation area, photogrammetry, accuracy evaluation

DOI: $10.25165 /$ j.ijabe.20181103.3012

Citation: Zhang H M, Yang J T, Baartman J E M, Li S Q, Jin B, Han W T. Quality of terrestrial data derived from UAV photogrammetry: A case study of Hetao irrigation district in northern China. Int J Agric \& Biol Eng, 2018; 11(3): 171-177.

\section{Introduction}

Raster digital elevation models (DEMs) can represent continuous topographic elevations above a common base level in two ways, as digital surface models (DSMs) and digital terrain models (DTMs). A DSM is a model in which each pixel has the value of the highest feature at the pixel location, and vegetation, structures, and water are filtered out of DTMs. DEMs are widely used in automated hydrological analyses and for the extraction of watershed characteristics, including slope steepness $^{[1]}$, slope

\section{Received date: 2016-11-18 Accepted date: 2017-11-20}

Biographies: Hongming Zhang, PhD, Professor, research interests: digital terrain analysis and land degradation, zhm@nwsuaf.edu.cn; Jiangtao Yang (Co-first author), MSc, research interests: water resources and architectural engineering, Email: jacktomm@nwsuaf.edu.cn; Jantiene E.M. Baartman, $\mathrm{PhD}$, research interests: land degradation and soil management, Email: jantiene.baartman@wur.nl; Shuqin Li, Professor, research interests: information engineering, Email: 1sq cie@nwsuaf.edu.cn; Bei Jin, PhD, research interests: agriculture economics and soil management, Email: jinbei85@163.com Xiaomei Yang, PhD, research interests: land degradation and environmental pollution, Email: xiaomei.yang@wur.nl; Lingtong Gai, $\mathrm{PhD}$, research interests: regional water resources management, Email: lingtong.gai@wur.nl; Coen J. Ritsema, research interests: land degradation and soil management, Email: coen.ritsema@wur.nl; Violette Geissen, research interests: land degradation and soil management, Email: violette.geissen@wur.nl.

*Corresponding author: Wenting Han, $\mathrm{PhD}$, Professor, research interests: technology of water saving in arid area, Institute of Water Saving Agriculture in Arid Area of China; Northwest A\&F University. Tel: +86-29-87091325, Email: hanwt2000@126.com. length ${ }^{[2]}$, direction of water flow ${ }^{[3,4]}$, drainage networks ${ }^{[5,6]}$, surface roughness of agricultural soils ${ }^{[7]}$, and flood simulation ${ }^{[8]}$. Procedures have been developed over the last 30 years that allow the use of geographic information system (GIS) and remote sensing (RS) to monitor any dynamic process for increasing the productivity of cropland, including water use, soil salinisation, crop condition, and topographic changes. Low-resolution DEMs, however, cannot be used in hydrological analyses to assess irrigation districts where the land is flat ${ }^{[9]}$.

Elevation data are usually obtained by three methods ${ }^{[10]}:$ (1) Field surveys: this method is the most accurate, but generating high-resolution DEMs for large areas is time-consuming, expensive, and difficult. (2) Existing topographic maps: high-resolution DEMs depend on map scale and are generated by upscaling spatial interpolation $^{[11]}$, but some of the DEM cells cannot represent the real terrain and are estimated by an interpolation algorithm based on the topographic maps. (3) Remote sensing: features of irrigation districts, such as irrigation networks and crop height, are not visible in satellite data. Technological advances have been made in recent decades for acquiring, storing, and mapping data, but affiliated research, e.g. airborne photogrammetry, interferometry, and techniques of light detection and ranging, can be costly for small areas of only a few square kilometres ${ }^{[12]}$. Recent developments in remote sensing with unmanned aerial vehicles (UAVs), also known as drones, have emerged from new, flexible, high-resolution technologies for the collection of topographic data. The spatial resolution of the data collected by 
UAVs can be much higher due to their low flight altitudes ${ }^{[13]}$. Data collection is also inexpensive. The production of orthophotos and DEMs has become completely digital, mostly automatic, and rapid.

Irrigated agriculture produces $40 \%$ of the food for human consumption globally and consumes $70 \%$ of the water demand ${ }^{[14]}$. The rapid population growth in recent decades has forced an increase in cropland productivity, particularly in water-limited areas ${ }^{[15,16]}$. The topography of agricultural land plays an important role in the quantification of runoff and sediment transport, because the presence of crops, crop residues, furrows, and ridges may affect the flow of surface water. The Hetao irrigation district (HID) is the third largest irrigation district in China, covering an area of $1.12 \mathrm{Mhm}^{2}, 51 \%$ of which is irrigated. It produces more than $35 \%$ of the wheat, sunflowers, and sugar beets in the Inner Mongolia Autonomous Region ${ }^{[17]}$. This area has a typically arid and semi-arid continental climate, and the irrigation water comes mainly from the Yellow River. The increasing demand for water for industrial and domestic uses and for generating hydroelectric power exacerbates the severity of water scarcity in this area. Optimising the efficiency of irrigation in this area is thus urgently needed. Obtaining high-resolution terrain maps for generating irrigation networks and classifying land use and crop conditions has become the main challenge. UAV applications can be used for re-planning forest roads ${ }^{[18]}$, monitoring crops $^{[19]}$, detecting archaeological sites ${ }^{[20]}$, surveying the effects of earthquakes $^{[21]}$, environmental surveying ${ }^{[22]}$, monitoring traffic ${ }^{[23]}$, and $3 \mathrm{D}$ reconstruction ${ }^{[24]}$. Various UAV-based civilian applications and accuracy analyses have been described ${ }^{[10,25-27]}$. The application and precision of DEMs derived from UAV stereo-photogrammetry, however, have not yet been verified or quantified in irrigated areas in China.

In this research, a UAV was used to capture aerial images of HID for generating DEMs. The accuracy of the DEMs was estimated by comparing them to ground-based measurements. The storage capacity of irrigation-channel networks plays an important role in precision irrigation, particularly the design of the networks and locations of the pumping stations. The capacity of an irrigation channel can be calculated from a raster map, e.g. a DEM, so the accuracy of channel widths derived from a DEM should be assessed. Both the vertical (depth) and horizontal (width) errors were also estimated in HID's irrigation-channel network.

\section{Materials and methods}

\subsection{Study area}

The HID is in the upper reaches of the Yellow River and is a closed rift basin that formed in the late Jurassic of Mesozoicperiod. It is the most important part of the Inner Mongolia Autonomous Region for producing food. The mean annual precipitation is only $155 \mathrm{~mm}$. The mean annual temperature is $7^{\circ} \mathrm{C}$, with monthly averages of $-10.1^{\circ} \mathrm{C}$ and $23.8^{\circ} \mathrm{C}$ in January and July, respectively. The mean annual pan evaporation (20 cm pan) is about $2000 \mathrm{~mm}^{[17]}$. Irrigation plays a dominant role in this region due to the low rainfall. Surface water from rivers, lakes, and snowmelt are the major sources of irrigation water. About $5.2 \times 10^{9} \mathrm{~m}^{3}$ of water are taken from the Yellow River each year to irrigate crops. The increasing demand for water for industrial and domestic uses and for generating hydroelectric power, however, exacerbates the severity of water scarcity in this basin. Decreases in precipitation and river flow have also been detected ${ }^{[28]}$. Various water-saving technologies and measures must thus be adopted for improving the management of furrowed and level-basin irrigation systems.

The soil in HID is frozen for about six months of the year. Soil salinity and groundwater levels rise and fall during the year due to irrigation infiltration and phreatic evaporation ${ }^{[29]}$. Four periods are identified associated with the rise or fall of the water table. The first period, from late March to mid/end of May, is when frozen soil water melts. Soils are frozen at the beginning of this period, and the groundwater level is at its lowest. The water table then rises as the soil water melts until early May, recharging the aquifer with the melted water infiltrating from the upper soil layers. The second period, from May to the end of September, is the crop growing season, where the evaporative demand is very high. The third period is from early October to early November. All crops are then harvested, and the fields are flooded to leach salts, improve soil structure by the freeze-thaw cycles in the upper layers, and provide sufficient soil moisture for subsequent crops. The fourth period is from early November to mid-March when the soil is frozen. The thickness of the frozen layer increases and the groundwater level decreases as the temperature decreases, because no recharge water is available from irrigation or rain.

The UAV was flown over two study areas in HID on the Loess Plateau in the Inner Mongolia Autonomous Region (red rectangles in Figure 1) near the Yellow River in China $\left(40^{\circ} 24 ' 40^{\prime \prime}-41^{\circ} 6^{\prime} 52^{\prime \prime} \mathrm{N}\right.$, $107^{\circ} 1^{\prime} 40^{\prime \prime}-107^{\circ} 53^{\prime} 13^{\prime \prime E}$ ). The total area is approximately $20000 \mathrm{~m}^{2}$, with an elevation range of 973.76-1037.01 $\mathrm{m}$ a.s.1. The two study areas are near the villages of Baleng in Dengkou County and Haifeng in Haiziyan County. The study areas have four main terrain features: normal channels, brick-lined channels, roads, and farmland (Figure 2).

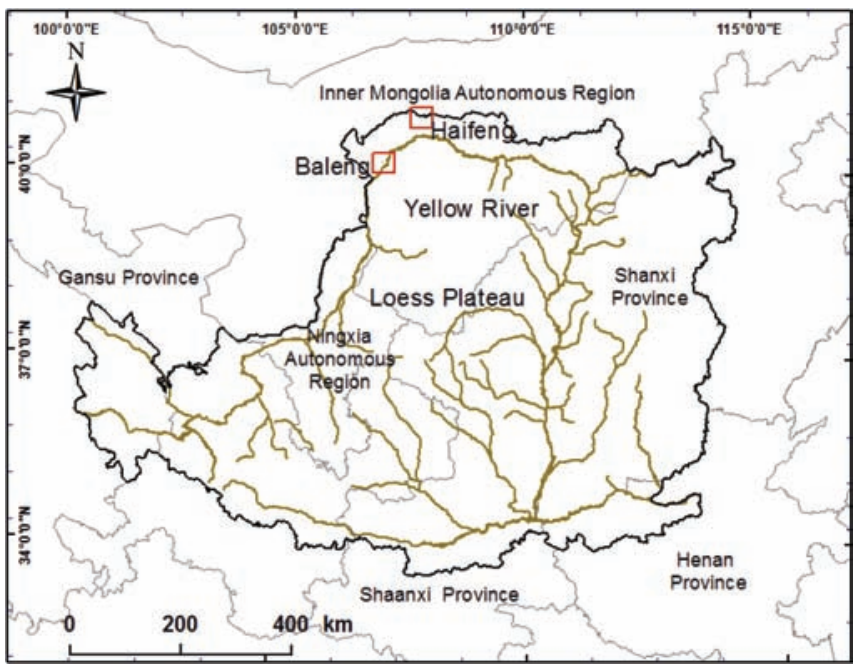

Figure 1 Study areas (red rectangles) near the villages of Haifeng and Baleng on the Loess Plateau (black line)

\subsection{Data processing and DEM generation by UAV}

DEMs contain data for the elevation of the terrain that can be used to derive contour lines. DEM quality control is needed for obtaining qualitative maps from images and involves the evaluation of interior and exterior accuracy. Interior accuracy can be defined by stereo measurements. Exterior accuracy compares the elevation of terrain points derived from DEMs with data from geodetic or GPS measurements. 


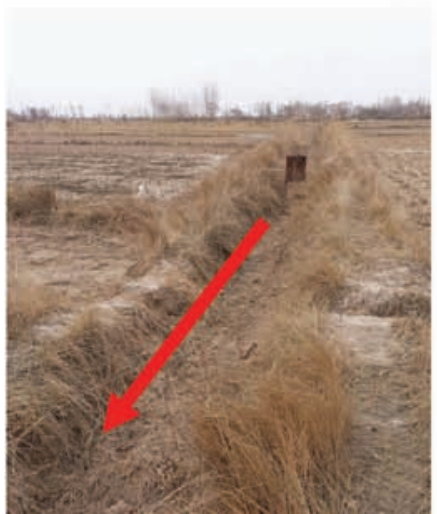

a. Normal channel (Feature A)

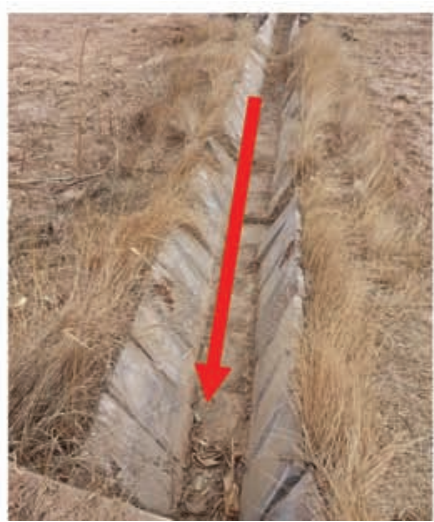

b. brick-lined channel (Feature B)

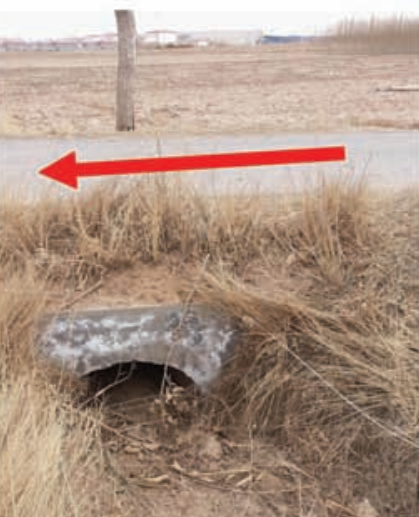

c. road (Feature C)

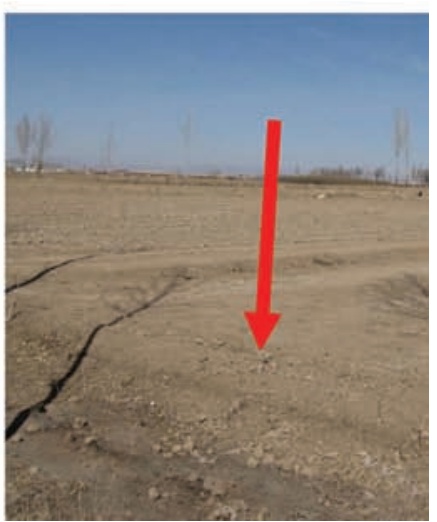

d. farmland (Feature D)

Figure 2 Terrain features in the study areas

This study used DEMs and orthophotos obtained from two UAV flights on 21 and 22 March 2016. Orthophotos are digital aerial photographs rectified to a DEM of the same area, giving the entire photo the same scale ${ }^{[30]}$. UAV flights are dependent on the weather, winds, and optimal flying heights ${ }^{[31]}$. Flying heights range from 80 to $300 \mathrm{~m}$, depending on the required image resolution. Wind speed must be $<10 \mathrm{~m} / \mathrm{s}$. Orthophotos are digital aerial photographs rectified to a DEM of the same area, giving the entire photo the same scale ${ }^{[30]}$. The DEMs and orthophotos were acquired by UAV-based photogrammetry using an AF1000 UAV (Anxiang Power Company Beijing, China), which is a robust, low-cost, light UAV constructed with styrofoam . It is a MAVinci fixed-wing airplane with a wingspan of $2.7 \mathrm{~m}$ and a speed of $14 \mathrm{~m} / \mathrm{s}$ (Figure 3) and can fly for a maximum of $70 \mathrm{~min}$ in low wind conditions. It was equipped with a SONY A5100 GX1 24 megapixel digital camera with an EF-M 22-mm lens. The device weighed $302 \mathrm{~g}$ and fully equipped weighed $418 \mathrm{~g}$. The UAV guidance system can be set to fully automatic, semi-manual, or manual. Take-off and landing on a flat surface can be automatic or manual. The Paparazzi autopilot ${ }^{[32]}$ based on the Arduino embedded system was used for automatic guidance. Aerial photographs were automatically mosaicked to create high-resolution orthophotos and DEMs using Agisoft Photoscan ${ }^{[33]}$. Approximately 1000 aerial images were acquired during each flight. Five ground checkpoints (GCPs) were measured before the flights using a Huace real-time kinematic (RTK) receiver (Shanghai, China). GPS surveying was used to georeference the data (painted black and white aluminium plates $40 \times 40 \mathrm{~cm}$ in size) for a total of 112 GCPs in the study areas (including the above five GCPs). RTK is a GPS tool for determining position and elevation with an accuracy as high as $\pm 1 \mathrm{~cm}^{[34]}$. The DEM error was considered to be the difference between the given value of a pixel and the true value ${ }^{[35]}$. The field observations (also referred to as 'true values') must be more accurate than the data collected for DEM generation to determine whether a DEM contains errors. The GCPs were used as reference points. RTK used GPS with a reference station in the field to determine locations. The ability to identify features of the terrain can differ among locations ${ }^{[10]}$, so the GCPs were distributed among four terrain features for comprehensively assessing the errors. Eighty-two of the 112 GCPs were in irrigation channels or ditches (41 were in normal channels, and 41 were in brick-lined channels), 28 pairs (56) GCPs located both side of the channels, left 26 GCPs located in the centre of channels. The widths of which where the 56 GCPs located were manually measured. Eleven of the GCPs were on roads, and 19 were on farmland. These field observations were made for determining both the horizontal and vertical accuracies of the UAV-derived DEMs.

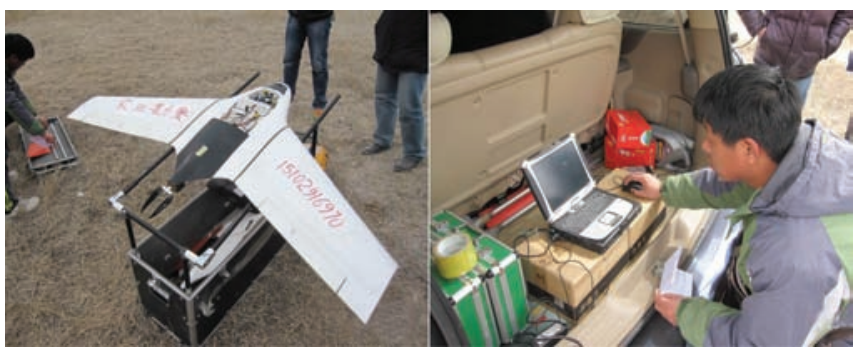

a. AF1000 UAV

b. Ground control station

Figure 3 UAV equipment

DEMs normally contain vegetation, structures, and water and are therefore DSMs and not DTMs, which would represent the soil surface. The structure of agricultural soil is continuously modified by farming activities, but the data were collected when the vegetation cover was low, the soil was frozen, and no crops were growing, so our DEMs could be considered as DTMs. The resolution of the DEM data was $0.15 \mathrm{~m}$ from a dense point cloud. Gauss Kruger projections were used in zones $6^{\circ}$ wide based on the Xian80 Geographical Coordinate System and the 1985 National Height Datum.

\subsection{Analysis of accuracy}

DEM errors are generally divided into three groups: systematic, blunders, or random ${ }^{[36]}$. Blunders can be assumed to have largely been removed if the data have been well reviewed before DEM generation. DEM errors can then be considered to be the sum of only systematic and random errors. Systematic errors are due to the procedures used to generate the DEM and follow fixed patterns that can cause bias or artefacts in the final DEM. Systematic errors can be removed or reduced if their causes are known. Random errors are those that remain in the data when systematic errors and blunders have been removed.

The accuracy of the analysis was assessed by comparing the UAV-derived DEM with the 112 measured GCPs in the study area used as references. The vertical error was calculated by subtracting the elevations measured at the 112 GCPs from the DEM elevations at the same points. The widths of the irrigation channels were measured manually (Figure 4a). The horizontal error was calculated by subtracting the channel widths measured at 56 of the 82 channel GCPs from the DEM widths at the same points. The 'Measure-Distance' tool in ArcGIS was used to measure the distance between two points, which was called the distance from the map (DFM). The capacity of an irrigation channel can be calculated from a raster map, e.g. a DEM, so 
channel widths can be calculated from DEMs by counting the numbers of grid cell (Figures $4 b$ and $4 c$ ). This distance was called the distance from the raster (DFR). The channel width is the Euclidean distance between the centres of the two grid cells where the GCPs are located. The DFR between point $a$ and $b$ can be calculated based on the vertical and horizontal cell numbers, the distance of point $\mathrm{a}$ and $\mathrm{b}$ can be calculated by following equation:

$$
d\left(a^{\prime}, b^{\prime}\right)=\sqrt{d\left(a^{\prime}, c^{\prime}\right)^{2}+d\left(b^{\prime}, c^{\prime}\right)^{2}}
$$

where, $d\left(a^{\prime}, b^{\prime}\right)$ is the distance of point $a^{\prime}$ and $b^{\prime} ; d\left(a^{\prime}, b^{\prime}\right)$ is the distance of point $a^{\prime}$ and $b^{\prime} ; d\left(b^{\prime}, c^{\prime}\right)$ is the distance of point $b^{\prime}$ and $c^{\prime}$.

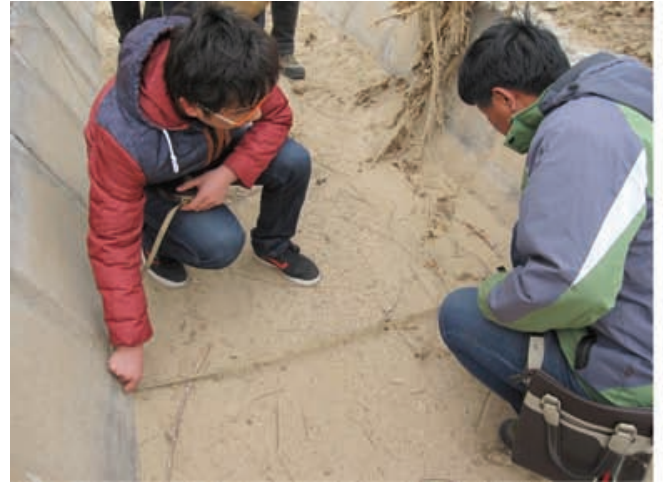

a. Manually

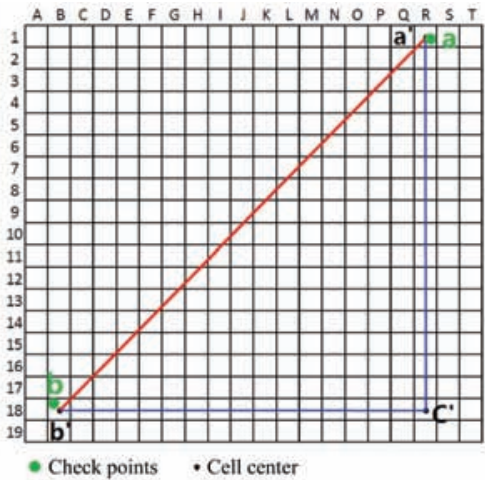

b. Theoretical DFR (red line) of two GCPs (points $\mathrm{a}$ and $\mathrm{b}$ )

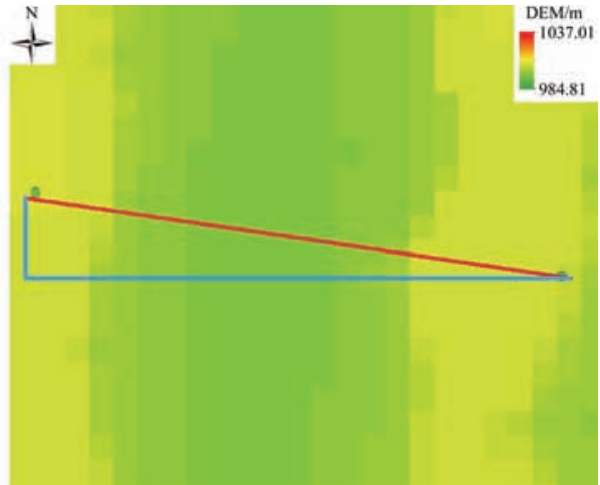

c. Actual DFR (red line) of two GCPs overlaying DEM data

Figure 4 Measurement of irrigation-channel width

Model performance is best assessed using a combination of metrics $^{[37]}$, so several common parameters for comparing UAV-derived DEMs and GCPs were calculated, including RMSE, mean absolute error (MAE), and standard deviation (SD):

$$
\begin{gathered}
R M S E=\sqrt{\frac{\sum_{i=1}^{n}\left(Z_{i G C P}-Z_{i D E M}\right)^{2}}{n}} \\
M A E=\frac{\sum_{i=1}^{n}\left|Z_{i G C P}-Z_{i D E M}\right|}{n} \\
S T D=\sqrt{\frac{\sum_{i=1}^{n}\left(\left|Z_{i G C P}-Z_{i D E M}\right|-M E\right)^{2}}{n}}
\end{gathered}
$$

where, $n$ is the number of GCPs; $Z_{i G C P}$ is the reference value (elevation for vertical error or distance for horizontal error) of the GCPs; $Z_{i D E M}$ is the value (elevation for vertical error or distance for horizontal error) for the corresponding grid cell in the DEMs.

\section{Results and discussion}

The errors determine the dispersion of the distribution of deviations between the measured elevations and the DEM data. A larger error corresponds to a higher dispersion between the two types of data. The number of GCPs differed in different areas; the area in the irrigation-channel network had more GCPs (Figure 5). This result was expected due to the importance of irrigation channels. The difference between the measured elevations and the $0.15 \mathrm{~m}$ DEM elevations ranged from $-9.87 \mathrm{~cm}$ to $29.1 \mathrm{~cm}$ (Figure 6), where negative and positive values imply that the DEM elevations were over- and underestimated, respectively. For the UAV-derived DEMs, $62.5 \%$ of the absolute errors were $<10 \mathrm{~cm}$, and $77.7 \%$ were $<15 \mathrm{~cm}$. These results for testing the accuracy of the elevation of points obtained from photogrammetric data indicated that using a low-cost UAV for data acquisition provided the required accuracy and could be used for agricultural monitoring.

Ouedraogo et al. ${ }^{[10]}$ suggested that positive errors could be caused by the compaction of soil by tractor wheels. Farming activities in the study area, however, had not yet started, but positive errors were still found, indicating that farming activity may influence the accuracy of DEMs, but random and systemic errors may have the largest impact.

The errors for the four types of terrain features were calculated separately. The maximum and minimum differences occurred at the normal channels (Feature A) and roads (Feature C), with values of 29.1 and $0.1 \mathrm{~cm}$, respectively. Absolute errors $>15 \mathrm{~cm}$ were mainly along channel edges. The presence of dry grass, trees, and crop residues beside the channels would influence the accuracy of $3 \mathrm{D}$ resolution. The descending order of absolute differences was Feature A $>$ Feature B $>$ Feature D $>$ Feature C. These results indicated that the DEMs derived from UAV photogrammetry could be sensitive to surface colour. The greater the contrast in colour, the smaller the errors.

RMSE, MAE, and SD for all 112 GCPs were 13.0, 10.7, and $6.8 \mathrm{~cm}$, respectively (Table 1). The UAV-derived DEMs were thus accurate, because their mean absolute differences did not exceed $0.15 \mathrm{~m}$. Point-based analyses of RMSEs can determine the relationship between topographic features and altitude. The maximum and minimum RMSEs were also at normal channels (Feature A) and roads (Feature C), with values of $16.5 \mathrm{~cm}$ and $6.7 \mathrm{~cm}$, respectively. This result also indicated that DEMs of agricultural watersheds can be generated from UAV photogrammetric data using Agisoft PhotoScan. The RMSEs had a range of $6.7-16.5 \mathrm{~cm}$. This method could be adopted for monitoring the growth of sunflowers and corn.

Table 1 Vertical errors in the UAV-derived DEMs

\begin{tabular}{cccccc}
\hline Error Type & Feature & Number of GCPs & RMSE/cm & MAE/cm & SD/cm \\
\hline & Total & 112 & 13.0 & 10.7 & 6.8 \\
Vertical & A & 41 & 16.5 & 13.9 & 8.8 \\
errors & B & 41 & 10.9 & 9.3 & 5.8 \\
& C & 11 & 6.7 & 4.6 & 4.8 \\
& D & 19 & 11.3 & 10.0 & 4.8 \\
\hline Horizontal & A & 28 & 8.2 & 6.4 & 5.8 \\
errors & B & 28 & 7.6 & 6.2 & 5.9 \\
\hline \multirow{2}{*}{ DFR errors } & A & 28 & 17.6 & 16.8 & 12.2 \\
& B & 28 & 12.7 & 11.4 & 9.5 \\
\hline
\end{tabular}



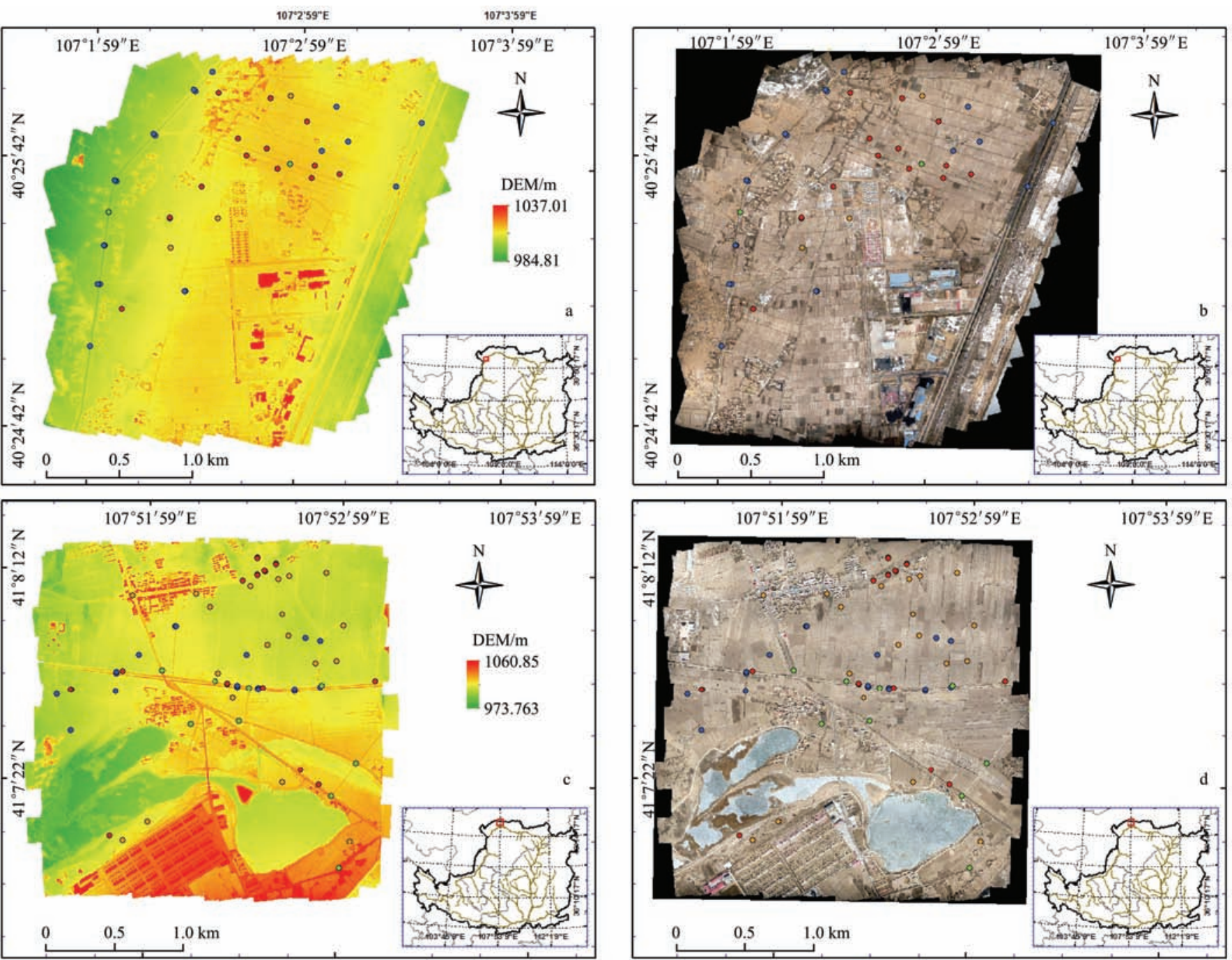

Note: DEM elevation (a) and orthophoto (b) near the village of Baleng in Dengkou County, Inner Mongolia Autonomous Region, China; DEM elevation (c) and orthophoto (d) near the village of Haifeng in Haiziyan County. The insets indicate the positions of the study areas on the Loess Plateau. The different colour dots in a and c indicate the GCPs, Feature A (red dots), Feature B (blue dots), Feature C (orange dots) and Feature D (green dots).

Figure 5 GCPs in the irrigation-channel network

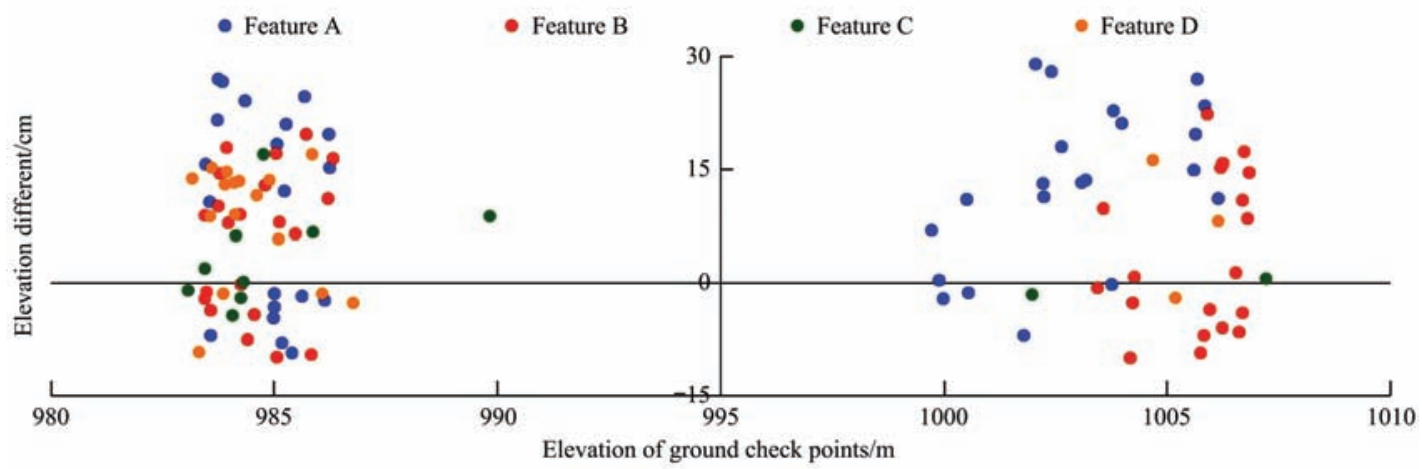

Note: Left clusters of data points is Haifeng village and right cluster is Baleng village.

Figure 6 Differences between the ground check points and the UAV-derived DEMs for the four terrain features

Nonlinear (parabolic) distortion overestimated the terrain elevation on the borders of image blocks when using the Agisoft Lens toolbox for $3 \mathrm{D}$ reconstruction. This shift has been referred to as 'bowl effect' by some users of Agisoft PhotoScan ${ }^{[10]}$. This kind of error can be evaluated by DFMs as horizontal errors (Table 1).

The accuracy of the calculated irrigation-channel widths was $8.4 \mathrm{~cm}$ (Table 1). Errors were larger for normal than brick-lined channels. The manual measurements and our calculations may have both contained errors, but the test indicated that the DEMs derived from UAV photogrammetry did not correspond well with the ground data. These errors demonstrated that horizontal errors do exist.

The errors in irrigation-channel width were larger for DFR than DFM (Table 1). The grid size influenced the DFR errors, so a DEM with a grid size of $1 \mathrm{~cm}$ was generated, which already reached the limitation of RTK accuracy. The DFR and DFM RMSEs became 9.0 and $8.6 \mathrm{~cm}$, respectively, but errors remained in this situation. This accuracy, however, met our targets for mapping the terrain of an irrigated area, monitoring crop growth, 
and determining the capacity of an irrigation-channel network. Many other factors can influence the accuracy of UAV-derived DEMs. Jaud et al. ${ }^{[26]}$ demonstrated that accuracy varied among the data-processing algorithms used in different programmes (e.g. MicMac and Agisoft PhotoScan). This effect on accuracy should be further evaluated in future studies. The correlation between flight height and error should be also assessed to quantify the increase in error in irrigated regions.

\section{Conclusions}

UAV photogrammetry has been widely used in recent years. The largest advantages are the speed of data collection, the density of measured points, and its affordability.

(1) This study indicates that the development of remote sensing using UAVs is a priority for economic and environmental reasons, especially in semiarid and arid areas where irrigation must be controlled. Compared with traditional mapping, this method can reduce operational costs where the weather is bad but retains sufficient accuracy.

(2) The results showed that UAV-based data could be used for DEM generation by photogrammetric techniques with a vertical accuracy of $13.0 \mathrm{~cm}$ a horizontal accuracy of $15.2 \mathrm{~cm}$, meeting the criteria of accuracy, and can generally be considered as a convenient tool for data collection for surveying the surface of irrigated areas. UAV photogrammetry can be a supplement to, or a replacement for, traditional terrestrial methods for image acquisition in small areas.

(3) UAV photogrammetry will be an essential tool that is rarely applied to the management of irrigated agricultural systems in these regions. The $3 \mathrm{D}$ models produced are satisfactory for analysing topographic texture. Some parameters, such as weather, vibrations, lens distortions, and software, directly affect the process and model accuracy. More research is needed to increase the accuracy of UAV-derived DEMs.

\section{Acknowledgements}

This work was financially supported by Major Project of National Key R \& D Plan from the MOST of China (2017YFC0403203), National Natural Science Foundation of China (41771315, 41301283, 61402374, 41371274, 41301507), Natural Science Foundation of Shaanxi Province (2015JM4142) and EU Horizon 2020 research and innovation programme (ISQAPER: 635750) and State Key Laboratory of Soil Erosion and Dryland Farming on the Loess Plateau (A314021402-1702). Sincere thanks to Wenshuai Zhang, Liyuan Zhang, Haixin Zhang for their help in field work. The author also appreciates the help from Yao Li, Meng Wang, Haiwen $\mathrm{Wu}$, for their help in data analysis. Thanks to Dr. William Blackhall for language edition. Thanks also to the anonymous reviewers who all made valuable comments that improved our paper.

\section{[References]}

[1] Chen Z D, Chen Y G, Chen X Y, Ma T W. An algorithm to extract more accurate slopes from DEMs. IEEE Geoscience and Remote Sensing Letters, 2016; 13(7): 939-942.

[2] Zhang H, Yang Q, Li R, Liu Q, Moore D, He P, Ritsema C J, Geissen V. Extension of a GIS procedure for calculating the RUSLE equation LS factor. Computers \& Geosciences, 2013; 52: 177-188.

[3] Su C, Feng C, Wang X, Huang Z, Zhang X. An efficient algorithm for assignment of flow direction over flat surfaces in raster DEMs based on distance transform. Earth Science Informatics, 2016; 9(2): 225 - 233.

[4] Zhou G, Sun Z, Fu S. An efficient variant of the priority-flood algorithm for filling depressions in raster digital elevation models. Computers \& Geosciences: Part A, 2016; 90: 87-96.

[5] Persendt F C, Gomez C. Assessment of drainage network extractions in a low-relief area of the Cuvelai Basin (Namibia) from multiple sources: LiDAR, topographic maps, and digital aerial orthophotographs. Geomorphology, 2016: 260: 32-50.

[6] Zhang H, Yao Z, Yang Q, Li S, Baartman J E M, Gai L, Yao M, Yang X, Ritsema C J, Geissen V. An integrated algorithm to evaluate flow direction and flow accumulation in flat regions of hydrologically corrected DEMs. Catena, 2017: 151: 174-181.

[7] Martinez-Agirre A, Alvarez-Mozos J, Gimenez R. Evaluation of surface roughness parameters in agricultural soils with different tillage conditions using a laser profile meter. Soil \& Tillage Research, 2016; 161: 19-30.

[8] Gomes T L, Magalhaes S V G, Andrade M V A, Franklin W R, Pena G C. Efficiently computing the drainage network on massive terrains using external memory flooding process. Geoinformatica, 2015; 19(4): 671-692.

[9] Pajares G. Overview and current status of remote sensing applications based on unmanned aerial vehicles (UAVs). Photogrammetric Engineering and Remote Sensing, 2015; 81(4): 281-329.

[10] Ouedraogo M M, Degre A, Debouche C, Lisein J. The evaluation of unmanned aerial system-based photogrammetry and terrestrial laser scanning to generate DEMs of agricultural watersheds. Geomorphology, 2014; 214: 339-355.

[11] Yang Q K, McVicar T R, Van Niel T G, Hutchinsond M F, Li L T, Zhang X $\mathrm{P}$. Improving terrain representation of a digital elevation model by reducing source data errors and optimising interpolation algorithm parameters: an example in the Loess Plateau, China . International Journal of Applied Eart Observation and Geoinformation (JAG), 2007; 9(3): 235-246.

[12] Eltner A, Baumgart P. Accuracy constraints of terrestrial Lidar data for soil erosion measurement: Application to a Mediterranean field plot. Geomorphology, 2015; 245: 243-254.

[13] Everaerts J, Lewyckyj N, Fransaer D. Pegasus: design of a stratospheric long endurance UAV system for remote sensing. The International Archives of the Photogrammetry, Remote Sensing and Spatial Information Sciences: Part B, 2004; 35 - 39 .

[14] Bin Abdullah K. Use of water and land for food security and environmental sustainability. Irrigation and Drainage, 2006; 55(3): 219-222.

[15] Tarolli P. High-resolution topography for understanding Earth surface processes: Opportunities and challenges. Geomorphology, 2014; 216: 295-312.

[16] Huang Y B, Thomson S J, Brand H J, Reddy K N. Development and evaluation of low-altitude remote sensing systems for crop production management. International Journal of Agricultural and Biological Engineering, 2016; 9(4): 1-11.

[17] Xu X, Huang G, Qu Z, Pereira L S. Assessing the groundwater dynamics and impacts of water saving in the Hetao Irrigation District, Yellow River basin. Agricultural Water Management, 2010; 98(2): 301-313.

[18] Akgul M, Demir M, Ozturk T, Topatan H, Budak Y E. Investigation of recreational vehicles maneuverability on forest roads by computer-aided driving analysis. Baltic Journal of Road and Bridge Engineering, 2016, 11(2): 111-119.

[19] Xue X Y, Tu K, Qin W C, Lan Y B, Zhang H H. Drift and deposition of ultra-low altitude and low volume application in paddy field. International Journal of Agricultural and Biological Engineering, 2014; 7(4): 23-28.

[20] Reinhold S, Belinskiy A, Korobov D. Caucasia top-down: Remote sensing data for survey in a high altitude mountain landscape. Quaternary International, 2016; 402: 46-60.

[21] Achille C, Adami A, Chiarini S, Cremonesi S, Fassi F, Fregonese L, Taffurelli L. UAV-based photogrammetry and integrated technologies for architectural applications-methodological strategies for the after-quake survey of vertical structures in Mantua (Italy). Sensors, 2015; 15(7): 15520-15539.

[22] Neugirg F, Stark M, Kaiser A, Vlacilova M, Della Seta M, Vergari F, et al Erosion processes in calanchi in the Upper Orcia Valley, Southern Tuscany, Italy based on multitemporal high-resolution terrestrial LiDAR and UAV surveys. Geomorphology, 2016; 269: 8-22.

[23] Zhou H L, Kong H, Wei L, Creighton D, Nahavandi S. Efficient Road Detection and Tracking for Unmanned Aerial Vehicle. IEEE Transactions on Intelligent Transportation Systems, 2015; 16(1): 297-309. 
[24] Zhou Z X, Gong J, Guo M Y. Image-based 3D reconstruction for posthurricane residential building damage assessment. Journal of Computing in Civil Engineering, 2016; 30(2): 14

[25] Krsak B, Blistan P, Paulikova A, Puskarova P, Kovanic L, Palkova J, et al. Use of low-cost UAV photogrammetry to analyze the accuracy of a digital elevation model in a case study. Measurement, 2016; 91: 276-287.

[26] Jaud M, Passot S, Le Bivic R, Delacourt C, Grandjean P, Le Dantec N. Assessing the accuracy of high resolution digital surface models computed by PhotoScan ${ }^{\circledR}$ and MicMac $\AA$ in sub-optimal survey conditions. Remote Sensing, 2016; 8(6): 18 .

[27] Ishiguro S, Yamano H, Oguma H. Evaluation of DSMs generated from multi-temporal aerial photographs using emerging structure from motion-multi-view stereo technology. Geomorphology, 2016; 268: 64-71.

[28] Yang T, Xu C Y, Shao Q X, Chen X, Lu G H, Hao Z C. Temporal and spatial patterns of low-flow changes in the Yellow River in the last half century. Stochastic Environmental Research and Risk Assessment, 2010; 24(2): 297-309.

[29] Yu R, Liu T, Xu Y, Zhu C, Zhang Q, Qu Z, Liu X, Li C. Analysis of salinization dynamics by remote sensing in Hetao Irrigation District of North China. Agricultural Water Management, 2010; 97(12): 1952-1960.

[30] Barrette J, August P, Golet F. Accuracy assessment of wetland boundary delineation using aerial photography and digital orthophotography.
Photogrammetric Engineering and Remote Sensing, 2000, 66 (4): 409-416.

[31] Ruzgienė B, Berteška T, Gečyte S, Jakubauskienė E, Aksamitauskas V Č. The surface modelling based on UAV Photogrammetry and qualitative estimation. Measurement, 2015; 73: 619-627.

[32] Royo P, Pastor E, Barrado C, Santamaria E, Lopez J, Prats X, Lema J M. Autopilot abstraction and standardization for seamless integration of unmanned aircraft system applications. Journal of Aerospace Computing Information and Communication, 2011; 8(7): 197-223.

[33] Agisoft L. Agisoft PhotoScan user manual. Professional edition, version 0.9. 0: AgiSoft LLC (Pub), Calgary, CA. 2013.

[34] Gan-Mor S, Clark R L, Upchurch B L. Implement lateral position accuracy under RTK-GPS tractor guidance. Computers and Electronics in Agriculture, 2007; 59(1-2): 31-38.

[35] Wechsler S P. Uncertainties associated with digital elevation models for hydrologic applications: A review. Hydrology and Earth System Sciences, 2007; 11(4): 1481-1500.

[36] Caruso V. Standards for digital elevation models. American Society for Photogrammetry and Remote Sensing (ASPRS) and American Congress on Surveying and Mapping (ACSM) annual convention proceedings, 1987; pp.159-166.

[37] Chai T, Draxler R R. Root mean square error (RMSE) or mean absolute error (MAE)?-Arguments against avoiding RMSE in the literature. Geoscientific Model Development, 2014; 7(3): 1247-1250. 